\title{
APLIKASI PENCARIAN PENJUALAN LAPTOP MENGGUNAKAN TEKNOLOGI WEB SCRAPING
}

\author{
Yan Watequlis Syaifudin ${ }^{1}$, Arida Ferti Syafiandini ${ }^{2}$, Hafizh Rizqi Prisadana ${ }^{3}$ \\ Program Studi Teknik Informatika, Jurusan Teknologi Informasi, Politeknik Negeri Malang \\ qulis@polinema.ac.id ${ }^{1}$,afsyafiandini@gmail.com ${ }^{2}$, hafizhrizqi46@gmail.com $^{3}$
}

\begin{abstract}
Abstrak
Dengan berkembangnya teknologi pada saat ini, kebutuhan terhadap perangkat keras (laptop) sangat dibutuhkan. Kini hampir semua kalangan pendidikan dan pekerjaan sudah menggunakan bantuan perangkat keras terutama laptop. Tanpa adanya perangkat keras (laptop) maka pekerjaan akan menjadi sulit untuk penyelesaiannya. Dengan alasan tersebut, tidak terhindarkan lagi perangkat keras terutama berupa laptop begitu sangat dibutuhkan, hal ini akan semakin dimanfaatkan bagi para penjual demi meraih banyak keuntungan, bisa dengan cara memanfaatkan penjualan melalui internet yakni berupa website e-commerce. Dengan banyaknya website ecommerce sekarang, kita dapat dengan mudah mengakses informasi barang dari mana saja baik dari harga, spesifikasi, dan bahkan melakukan transaksi pembelian. Hal ini dapat menghemat waktu dan biaya bagi calon pembeli, karena tidak perlu datang ke toko langsung sehingga dari tempat duduk saja mereka dapat mengambil keputusan dengan mudah dan cepat karena adanya website e-commerce seiring berkembangnya teknologi serta kemudahan dalam pengkasesan internet. Akan tetapi website e-commerce sekarang telah banyak dibangun dan digunakan oleh para penjual hal tersebut terkadang membuat para pembeli sulit untuk memilih barang yang dicari dikarenakan banyaknya website e-commerce yang beredar luas di internet. Maka dari itu dibutuhkan sebuah aplikasi yang dapat memudahkan orang dalam pencarian barang terutama sebagai objek penelitian dalam studi kasus kali ini yakni perangkat keras berupa laptop sebagai barang kebutuhan penting saat ini dengan menggunakan teknologi web scraping dalam pencarian obyek laptop berbasis web, dan dengan menerapkan arsitektur Representational State Transfer (REST).
\end{abstract}

Kata kunci: Web scraping, Pencarian laptop, Arsitektur Representational State Transfer (REST).

\section{Pendahuluan}

Perkembangan teknologi informasi dari tahun ke tahun yang semakin cepat, menjadi tantangan berat bagi pengguna teknologi informasi. Hal tersebut mendorong setiap sektor organisasi baik formal, informal maupun lembaga lembaga lain untuk dapat memanfaatkan teknologi sebagai penunjang kegiatan kerja. Tujuannya untuk menghasilkan informasi yang cepat, tepat dan akurat. Kini teknologi internet sudah tidak asing lagi. Kebutuhan masyarakat akan informasi cepat sangat dibutuhkan dan informasi dapat diakses oleh siapa saja, kapan saja, di mana saja. Tentu dalam penggunaannya membutuhkan sebuah perangkat keras bisa berupa komputer, handphone dan laptop yang pada zaman modern sangat diperlukan.

Kini hampir semua kalangan pendidikan dan pekerjaan sudah menggunakan bantuan perangkat keras terutama laptop. Tanpa adanya perangkat keras (laptop) maka pekerjaan akan menjadi sulit untuk penyelesaiannya. Laptop sekarang merupakan barang kebutuhan sehari-hari bagi kalangan orang pekerja karena mudah dibawa berpindah tempat kemana saja. Dengan alasan tersebut, tidak terhindarkan lagi perangkat keras terutama berupa laptop begitu sangat dibutuhkan, hal ini akan semakin dimanfaatkan bagi para penjual demi meraih banyak keuntungan, bisa dengan cara memanfaatkan penjualan melalui internet yakni berupa website e-commerce.

Dengan banyaknya website e-commerce sekarang, kita dapat dengan mudah mengakses informasi barang dari mana saja baik dari harga, spesifikasi, dan bahkan melakukan transaksi pembelian. Hal ini dapat menghemat waktu dan biaya bagi calon pembeli, karena tidak perlu datang ke toko langsung sehingga dari tempat duduk saja mereka dapat mengambil keputusan dengan mudah dan cepat karena adanya website ecommerce seiring berkembangnya teknologi serta kemudahan dalam pengkasesan internet. Akan tetapi website e-commerce sekarang telah banyak dibangun dan digunakan oleh para penjual hal tersebut terkadang membuat para pembeli sulit untuk memilih barang yang dicari dikarenakan banyaknya website e-commerce yang beredar luas di internet. Dengan begitu sudah pasti kita melakukan cara manual yaitu mengunjungi satu per-satu website e-commerce untuk mengetahui 
informasi perbandingan harga mengenai barang yang dicari, serta terkait masalah kebijakan dan aturan tersendiri pada masing-masing website $e$ commerce dalam lingkup penyajian informasi.

Dari permasalahan tersebut, perlu dibangun sebuah aplikasi yang dapat memudahkan dalam pencarian barang terutama sebagai objek penelitian dalam studi kasus kali ini yakni perangkat keras berupa laptop sebagai barang kebutuhan penting saat ini dengan menggunakan teknologi web scraping. Maka dari itu penulis mengambil kesimpulan untuk membuat penelitian tentang aplikasi pencarian penjualan laptop dengan memanfaatkan metode scraping dan implementasi arsitektur Representational State Transfer (REST) berbasis web.

Tujuan dari penelitian ini adalah untuk menerapkan teknologi Web Scraping dan implementasi arsitektur REST yang dapat membantu orang untuk melakukan pencarian atau tracking seperti pada website-website e-commerce terhadap barang berupa perangkat keras (laptop). Dengan implementasi REST yang akan dibuat diharapkan dapat melakukuan pengambilan data dari web server e-commerce yang digunakan sehingga data yang diperoleh akan ditampilkan pada pembuatan aplikasi sistem.

Rumusan Masalah berdasarkan latar belakang masalah diatas adalah bagaimana menerapkan web scraping dan implementasi REST pada aplikasi pencarian penjualan laptop?

Metode penelitian

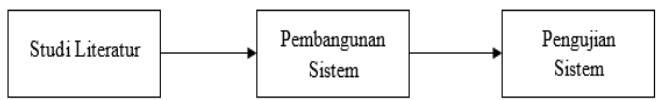

Gambar 1. Tahapan Kerangka Kerja Penelitian

Pada gambar 1 diatas terdapat beberapa tahapan penelitian yang dilakukan, berikut penjelasannya :

1. Studi Literatur.

Pada tahapan ini, penulis melakukan studi mengenai web scraping, web service, RESTFul dan API yang diperoleh dari buku-buku baik lokal maupun internasional, artikel-artikel, jurnal-jurnal, serta e-book dari internet serta pemahaman tentang alur sistem yang akan di bangun pada aplikasi pencarian penjualan laptop menggunakan teknologi web scraping.

2. Pengembangan Sistem

- Pengambilan Data.

- Website E-commerce

Data yang digunakan pada penelitian ini berupa data informasi mengenai barang laptop yang didapat dari beberapa website e-commerce yang terdapat barang penjualan laptop. Data informasi laptop tersebut terdiri dari beberapa kriteria antara lain nama barang, gambar barang, harga barang dan rating barang. Berikut daftar website e-commerce yang digunakan pada penelitian ini :

- elevenia.com

- bukalapak.com

- blibli.com

- blanja.com

- mataharimall.com

Berdasarkan daftar website e-commerce di atas, penulis mengambil daftar website tersebut dikarenakan pada masing-masing website merupakan situs/portal e-commerce yang patut diperhitungkan dalam angka jumlah ketertarikan jual beli pasar elektronik di indonesia. Lima website e-commerce tersebut merupakan deretan website papan atas yang angka jual beli pengunjungnya begitu besar dan pesat perkembangannya. Selain itu dikarenakan juga ke lima website e-commerce tersebut terdapat kategori penjualan barang berupa laptop sesuai dengan kebutuhan sistem pada pembuatan aplikasi pencarian penjualan laptop.

- Metode Web Scraping

Pada pembangunan sistem apikasi pencarian penjualan laptop, penulis menggunakan metode web scraping. Web scraping pada sistem berperan untuk mengambil menampilkan data yang di ambil berdasarkan implementasi RESTful, yaitu untuk mengambil data barang berupa nama barang, gambar barang, harga barang dan rating barang.

- Tools

1. Yahoo API

Yahoo API service adalah sebuah layanan yang disediakan oleh Yahoo untuk para web developer dengan berbagai macam fitur, salah satunya scraping / crawling. Peran Yahoo API pada pembangunan sistem yaitu untuk mendapatkan data HTML dari proses "GET" RESTful.

\section{RESTful}

Dalam pembangunan sistem ini, penulis melakukan pengambilan data terhadap website e-commerce menggunakan metode RESTful. Penggunaan terdapat pada proses method HTTP "GET" untuk mendapatakan data HTML barang pada website e-commerce yang digunakan.

\section{Pengujian Sistem}

Setelah sistem sudah selesai dibuat, maka dilakukan pengujian yang merupakan tahapan dimana sistem akan dijalankan. Pada tahap ini 
diperlukan sebagai ukuran bahwa sistem dapat dijalankan sesuai tujuan dan harapan. Sistem akan diuji menggunakan skema blackbox. Setiap modul (function) yang ada di sistem akan dievaluasi menggunakan variasi inputan kata kunci pencarian

Landasan Teori

E-commerce atau bisa disebut perdagangan elektronik merupakan sebuah aktivitas yang berakitan dengan pembelian, penjualan, pemasaran barang maupun jasa dengan memanfaatkan teknologi internet. E-commerce juga melibatkan aktivitas yang berhubungan dengan proses transaksi secara online yang dilakukan langsung oleh komputer atau penggunaan jaringan.

Web Service

Definisi web service adalah standar yang digunakan untuk melakukan pertukaran data antar aplikasi atau sistem, karena aplikasi yang melakukan pertukaran data bisa ditulis dengan bahasa pemrograman yang berbeda atau berjalan pada platform yang berbeda. Contoh implementasi dari web service antara lain adalah SOAP dan REST.

\section{Representational State Transfer (REST)}

REST (REpresentational State Transfer) merupakan standar arsitektur komunikasi berbasis web yang sering diterapkan dalam pengembangan layanan berbasis web. Umumnya menggunakan HTTP (Hypertext Transfer Protocol) sebagai protocol untuk komunikasi data. REST pertama kali diperkenalkan oleh Roy Fielding pada tahun 2000. Pada arsitektur REST, REST server menyediakan resources (sumber daya/data) dan REST client mengakses dan menampilkan resource tersebut untuk penggunaan selanjutnya. Setiap resource di-identifikasi oleh URIs (Universal Resource Identifiers) atau global ID. Resource tersebut direpresentasikan dalam bentuk format teks, JSON atau XML. Pada umumnya formatnya menggunakan JSON dan XML.

Pada gambar di bawah, dijelaskan tentang metode http yang umum digunakan dalam metode REST :

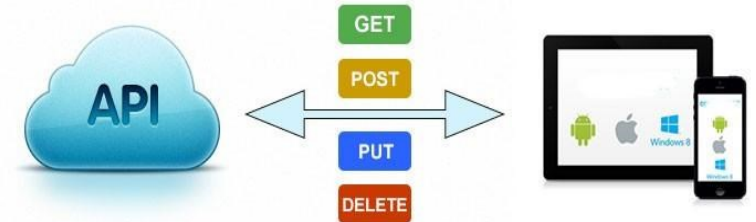

Gambar 2. Proses Implementasi (REpresentational State Transfer) REST

- GET, menyediakan hanya akses baca pada resource

- POST, digunakan untuk memperbarui
Resource yang ada atau membuat resource baru

- PUT, digunakan untuk menciptakan resource baru

- DELETE, digunakan untuk menghapus resource

Web API

Aplication Programming Interface (API) adalah kumpulan fungsi, perintah, atau protokol untuk menggantikan bahasa yang digunakan dalam system call dengan bahasa yang lebih mudah dimengerti. Sedangkan Web API adalah API yang bekerja di atas teknologi web yang menerima pesanan dari klien dan memberikan respon yang sesuai melalui protokol atau aturan tertentu. Web API lebih populer dengan sebutan web service, karena API tersebut memberikan layanan service yang diminta oleh klien.

Yahoo Aplication Programming Interface Service (APIS)

Yahoo APIS merupakan suatu layanan dalam pengambilan data API pada sebuah web server. Biasanya digunakan apabila terdapat sebuah web server yang tidak membuka atau menyediakan layanan API. Kini rata-rata hampir setiap web server tidak menyediakan layanan API dikarenakan alasan keamanan data pada pihak web server itu sendiri. Hal tersebut bisa dimanfaatkan dengan penggunaan layanan dari Yahoo APIS. Yahoo APIS memiliki proxy yaitu https://corsanywhere.herokuapp.com/. Di dalam pelayanan Yahoo APIS terdapat beberapa function dan variabel yang berguna untuk menjalankan dan melakukan pengambilan data pada web server yang ingin di ambil datanya melalui elemen-elemen HTML yang digunakan web server tersebut.

\section{Web Scraping}

Web scraping adalah pengambilan sebuah dokumen semi-terstruktur dari internet, umumnya berupa halaman-halaman web dalam bahasa markup seperti HTML atau XHTML, dan menganalisis dokumen tersebut untuk diambil data tertentu dari halaman tersebut. Istilah gampangnya yaitu pengambilan konten dari situs satu ke situs lain. Web scraping banyak digunakan para blogger / pemilik situs web untuk mengalihkan kata kunci yang dicari visitor ke situs lain yang dirasa paling lengkap misal google, wikipedia jika artikel yang dicari tidak ada. Tidak menutup kemungkinan juga scraping web ini digunakan untuk artikel dimana isi kontenya langsung diambil dari situs lain misal konten dari wikipedia. Contohnya pada pesonainformatika.com misalkan kata kunci yang dicari tidak ditemukan, maka otomatis akan melakukan scraping dari situs wikipedia berdasarkan kata kunci atau keyword yang dicari.

Pemrograman Web 
PHP

Pengertian PHP adalah bahasa pemrograman script server side yang didesain untuk pengembangan web. Dimana PHP ini merupakan singkatan dari Hypertext prepocessor yang digunakan sebagai script untuk memperindah tampilan website. Selain itu PHP juga digunakan bersamaan dengan bahasa pemrograman lainnya seperti bahasa pemrograman HTML dan java script.

Salah satu keunggulan yang dimiliki PHP adalah kemampuannya untuk melakukan koneksi ke berbagai macam software sistem manajemen basis data atau Database Management Sistem (DBMS), sehingga dapat menciptakan suatu halaman web dinamis. PHP mempunyai koneksitas yang baik dengan beberapa DBMS seperti Oracle, Sybase, mSQL, MySQL, Microsoft SQL Server, Solid, PostgreSQL, Adabas, FilePro, Velocis, dBase, Unix dbm, dan tidak terkecuali semua database ber-interface ODBC.

\section{CodeIgniter (CI)}

CodeIgniter adalah sebuah web application framework yang bersifat open source digunakan untuk membangun aplikasi web. Tujuan utama pengembangan Codeigniter adalah untuk membantu developeruntuk mengerjakan aplikasi lebih cepat daripada menulis semua code dari awal. Codeigniter menyediakan berbagai macam library yang dapat mempermudah dalam pengembangan. CodeIgniter diperkenalkan kepada publik pada tanggal 28 Februari 2006. CodeIgniter sendiri dibangun menggunakan konsep ModelView-Controller development pattern.

HTML

HTML atau singkatan dari Hypertext Markup Language ini merupakan sebuah bahasa markup pada internet khususnya web berupa kode dan simbol. Kode dan simbol tersebut nantinya akan ditempatkan kedalam sebuah file dengan tujuan untuk dimunculkan pada sebuah website. Fungsi dari HTML sendiri adalah digunakan untuk membuat sebua website. HTML ini diibaratkan sebagai sebuah pondasi dari sebuah website. Karena jika sebuah website tidak memiliki HTML maka para pembuat website tidak dapat untuk menggunakan bahasa markup lainnya seperti CSS yang digunakan utuk mendesain Website, lalu Javascript, ataupun PHP.

\section{XAMPP}

XAMPP adalah software web server apache yang di dalamnya tertanam server MySQL yang didukung dengan bahasa pemrograman PHP untuk membuat website yang dinamis. XAMPP sendiri mendukung dua system operasi yaitu windows dan Linux. Di dalam XAMPP ada tiga komponen utama yang di tanam di dalamnya yaitu web server
Apache, bahasa pemrograman dan MySQL (database). Berikut adalah penjelasannya :

1. Apache

Apache merupakan web server yang digunakan untuk menampilkan website di internet seperti menggunakan Mozilla fire fox, Google Crome, IE, Safari, dll berdasarkan kode-kode yang di tulis di dalam website tersebut baik menggunakan bahasa pemrograman HTML maupun PHP yang mengambil suatu database yang dibangun di MySQL, sehingga terbentuklah sebuah website yang dapat di lihat di Mozilla fire fox dan kawan-kawannya. Apache sendiri bersifat opensource sehingga dapat digunakan oleh siapa saja dan dikembangkan oleh siapa saja tentunya bagi yang mampu mengembagkannya.

2. Bahasa Pemrograman

Bahasa komputer adalah merupakan suatu set pemrograman yang digunakan untuk membuat suatu program komputer. Bahasa komputer biasa dikenal dengan nama bahasa pemrograman. Program komputer atau software sendiri adalah suatu set instruksi yang harus dijalankan oleh komputer pada saat komputer dihidupkan atau ketika diperintahkan oleh pengguna komputer. Bahasa pemograman menggunakan kata-kata unik yang menjadi kode untuk menjalankan perintah tertentu pada komputer.

3. MySQL

MySQL dapat digunakan untuk membuat dan mengola database beserta isinya. Kita dapat memanfaatkan MySQL untuk menambahkan, mengubah dan menghapus data yang berada dalam database. Artinya data-data yang dikelola dalam database akan diletakkan pada beberapa tabel yang terpisah sehingga manipulasi data akan menjadi jauh lebih cepat. MySQL dapat digunakan untuk mengelola database mulai dari yang kecil sampai dengan yang sangat besar. MySQL juga dapat menjalankan perintah-perintah Structured Query Language (SQL) untuk mengelola database-database yang ada di dalamnya. Hingga kini, MySQL sudah berkembang hingga versi 5. MySQL 5 sudah mendukung trigger untuk memudahkan pengelolaan tabel dalam database.

\section{Pembahasan}

Peracangan sistem dalam penelitian ini 
menggunakan Uml yaitu : Use Case,Activity dan class Diagram

\section{Gambar 3. Use case diagram}

Gambar 3 adalah use case diagram aplikasi destission diamana user dapat mencari objek yaitu berupa laptop, melihat hasil pencarian dan memilih barang yang diinginkan.

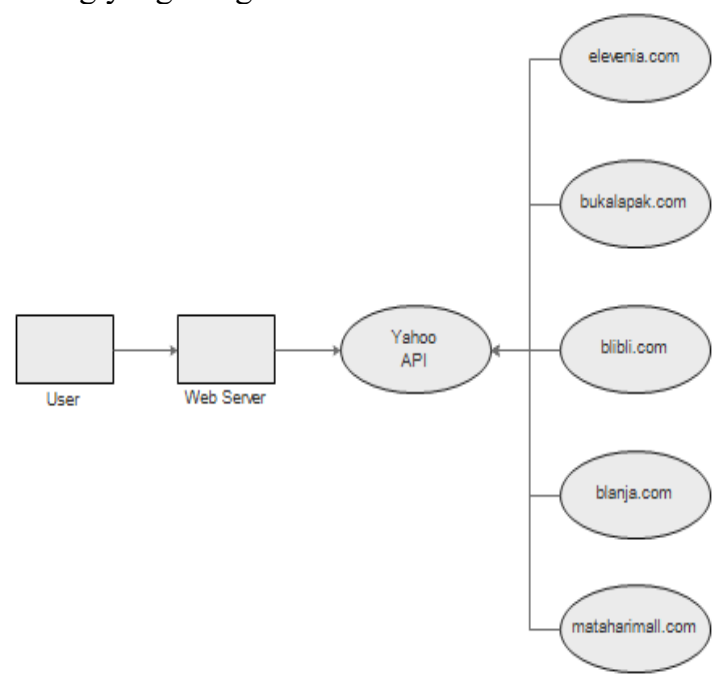

Gambar 4. Arsitektur Aplikasi Alur Sistem

Berdasarkan gambar 4 di atas merupakan arsitektur aplikasi alur pada sistem. Terdapat user atau pengguna kemudian web server merupakan aplikasi sistem. Yahoo API merupakan service pada sebuah layanan pada sistem yaitu untuk melakukan scraping data barang berupa nama barang, gambar barang, harga barang dan rating barang terhadap website e-commerce yang digunakan yaitu elevenia.com, bukalapak.com, blibli.com, blanja.com dan mataharimall.com.

Tahap ini dilakukan sebelum melakukan coding. Tahap ini bertujuan untuk memberikan gambaran apa yang seharusnya dikerjakan dan bagaimana tampilannya. Tahap ini membantu dalam menspesifikasikan kebutuhan hardware dan sistem sertamen pendefinisian arsitektur sistem secara keseluruhan.

Implementasi Antarmuka

Implementasi sistem merupakan tahap penerapan atau pembuatan sistem berdasarkan rancangan yang di lakukan pada bab analisis dan perancangan . Setelah aplikasi dibuat, maka tahap selanjutnya adalah menjalankan aplikasi pada browser. Hanya terdapat satu user pada aplikasi pencarian penjualan laptop. Berikut ini adalah penjelasan mengenai aplikasi pencarian penjualan laptop.

- Implementasi Halaman Utama (Home)
Halaman awal (home) adalah halaman pertama yang berisi tentang penginputan kata kunci untuk barang yang di cari yakni berupa laptop. Pada halaman ini user diminta untuk mengetikkan kata kunci pada kolom keyword laptop.

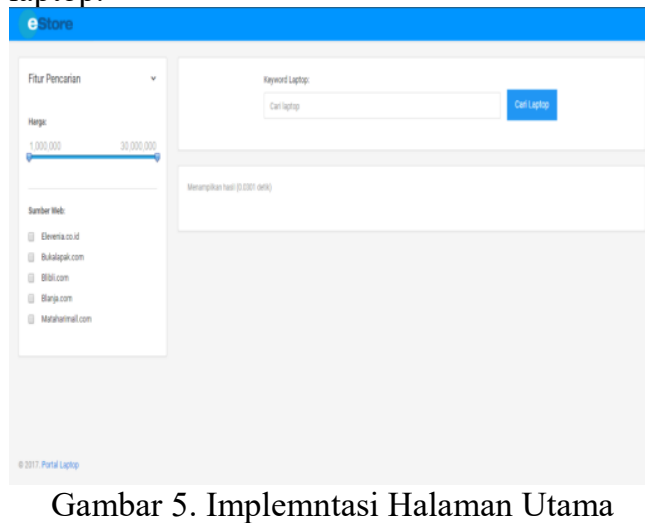

(Home)

- Implementasi Hasil Pencarian

Halaman hasil pencarian adalah halaman yang menampilkan hasil pencarian berdasarkan keyword laptop yang diinputkan. Pada halaman ini user dapat memilih barang yang ingin di cari sesuai dengan kata kunci yang diinputkan pada kolom keyword laptop.

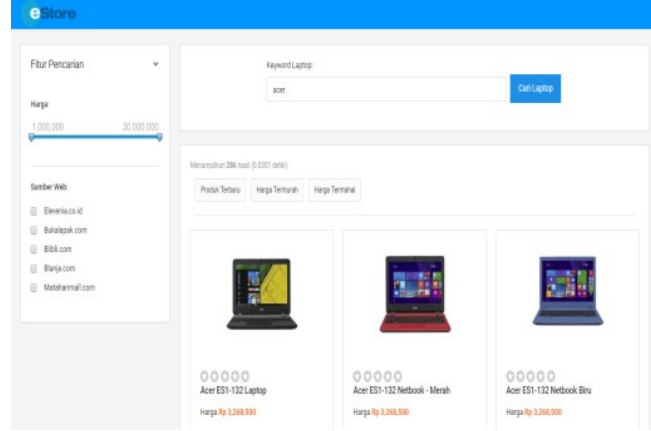

Gambar 6. Implementasi Halaman Hasil Pencarian

\section{Kesimpulan}

Berdasarkan penelitian yang dilakukan oleh penulis pada aplikasi pencarian penjualan laptop menggunakan teknologi web scraping pengembangan sistem dilakukan dengan cara menerapkan penggunaan web service dan implementasi RESTFul, maka dapat ditarik kesimpulan sebagai berikut :

1. Metode web scraping yang digunakan untuk mendapatkan data harga barang, data rating barang, nama barang dan gambar barang.

2. Pemanfaatan API Yahoo Service untuk mendapatkan data barang berupa laptop kemudian diolah agar sesuai dengan kebutuhan sistem yang dibangun.

3. Dalam melakukan proses penyajian data pada aplikasi dengan website e-commerce yang 
digunakan, perlu didefinisikan kategori secara spesifik untuk hasil pencarian di website ecommerce yang digunakan agar hasil yang ditampilkan oleh aplikasi sistem dengan website e-commerce yang digunakan sama hasilnya

\section{Daftar Pustaka}

Angga Purwoko, Eko Sediyono and Adi Setiawan, "Analisis dan Implementasi Restful Web Service Untuk Mobile Environment Pada GIS Lahan Pangan Kabupaten Minahasa Tenggara", 2014.

Damar Riyadi, "Rancang Bangun Web Service Untuk Perbandingan Harga Pengiriman Dengan Metode Web Scrapping dan Pemanfaatan API", Nov. 2013.

Edhy Sutantal and Khabib Mustofa, "Kebutuhan Web Service Untuk Sinkronisasi Data Antar Sistem Informasi Dalam E-Gov Di Pemkab Bantul Yogyakarta”, Mei. 2012.

Fauzan Natsir, Husni Thamrin, M.T., Ph. D and Aris Rakhmadi, S.T., M.Eng, "Implementasi Web Service Pada Aplikasi Kamus Bahasa Indonesia", Jun. 2013.

Febri Nugroho, "Sistem Penjualan Pada Perangkat Bergerak Berbasis Android Menggunakan Web Service", Feb. 2016.
Hilmi Taib, "Implementasi Fungsi Rest Pada Web Service Untuk Portal Berita Di SMK Islam Al Hikmah Mayong Jepara", Jan. 2015.

Ilham, Norhikmah and Dhiya Ulhaq Zulha Alamsyah, "Implementasi Web Service Dalam Pencarian Objek Wisata Berbasis Android", Feb.2017.

Nurwanda Oktaria , Satrio Agung Wicaksono, S.Kom., M.Kom., and Denny Sagita Rusdianto, S.Kom., M.Kom., "Perancangan dan Implementasi Sistem Informasi Semester Pendek PTIIK Menggunakan Integrasi Web Service Siakad UB".

Iqbal Firdaus, Dhanang Sukmana Adi and Fredi Aji Noorhadi, "Rancang Bangun E- Resto Menggunakan Web Services Untuk Restoran Family di Kotamadya Surakarta”, 2014.

Muhamad Aminudin Rahman, Imam Kuswardayan and Ridho Rahman Hariadi, "Perancangan dan Implementasi RESTful Web Service untuk Game Sosial Food Merchant Saga pada Perangkat Android", 2013.

Ninis Insiyah Masyhur, Kasim and Irmawati, "Rancang Bangun Web Service (Studi Kasus : Layanan SIM Inventaris Barang)", 2015.

Penidas Fiodinggo Tanaem, Danny Manongga and Ade Iriani, "RESTFul Web Service Untuk Sistem Pencatatan Transaksi Studi Kasus PT. XYZ”, Apr. 2016

Yuli Fauziah, "Aplikasi Iklan Baris Online menggunakan Arsitektur REST Web Service", 2 Jan. 2013. 